\title{
Sand Production Prediction Model for Tight Sandstone Oil Reservoirs
}

\author{
Zhan-dong Li $\mathbb{D}^{1,2,3,4}$ Hong Pang ${ }^{1}{ }^{3}{ }^{3}$ Zhong Li $\mathbb{D}^{5},{ }^{5}$ Hai-xiang Zhang $\mathbb{D}^{1,2,3}$ \\ Dian-ju Wang $\mathbb{D}^{2,3}$ and Ji Li $\mathbb{1}^{2,3}$ \\ ${ }^{1}$ Key Laboratory of Gas Hydrate Efficient Development of Heilongjiang, Daqing 163318, China \\ ${ }^{2}$ College of Offshore Oil \& Gas Engineering, Northeast Petroleum University, Heilongjiang Daqing 163318, China \\ ${ }^{3}$ College of Offshore Oil and Gas Engineering, Northeast Petroleum University, Daqing 163318, China \\ ${ }^{4}$ Sanya Offshore Oil \& Gas Research Institute, Northeast Petroleum University, Hainan Sanya 572025, China \\ ${ }^{5}$ CNOOC Research Institute, Beijing 100027, China
}

Correspondence should be addressed to Zhan-dong Li; 13644593771@163.com

Received 15 May 2020; Revised 18 July 2020; Accepted 30 September 2020; Published 17 October 2020

Academic Editor: Keliu Wu

Copyright (c) 2020 Zhan-dong Li et al. This is an open access article distributed under the Creative Commons Attribution License, which permits unrestricted use, distribution, and reproduction in any medium, provided the original work is properly cited.

Tight oil is an important unconventional resource, and sand production is an inevitable challenge during the field development. In this paper, based on data from the Daqing oilfield in Songliao Basin, the sand production of the tight sandstone oil reservoir is studied from the perspective of seepage and in situ stress distribution. Based on the combination of the formation fluid seepage law and the stress distribution around the well, a sand production prediction model is proposed to quantitatively estimate the sand production rate. The sand production prediction model is built based on the derivation of the sand production rate, which is well validated against the field data in the Daqing field with a relative error of $4.38 \%$.The following conclusions are drawn: (1) after the critical pressure difference is exceeded, the sand production rate is smaller with a higher flowing bottom-hole pressure; (2) a smaller sand production radius makes the formation more unstable and causes a more severe sand production; and (3) various sand production rates exhibit due to different permeabilities. A larger permeability results in a higher sand production rate. The findings of this study can help for sand production prediction in the tight sandstone oil reservoir.

\section{Introduction}

Tight oil and gas is a popular energy source in the oil industry, which supports the oil and gas revolution [1]. According to statistics, the total reserves of global tight oil reservoirs are about $9294 \times 10^{8} \mathrm{t}$, and the technically recoverable reserves are about $460 \times 10^{8} \mathrm{t}$, among which more than $60 \%$ of the tight oil resources are mainly concentrated in 6 countries including Russia, the United States, China, Libya, Argentina, and Australia [2]. The technically recoverable amount of tight oil in the United States is about $81.2 \times 10^{8} \mathrm{t}$, more than six times that of China. Although there are abundant resources in tight oil reservoirs, the recovery rate is generally low. In the Bakken formation in North America, for example, as one of the earliest tight reservoirs in the world, the average recovery from natural depletion in the Bakken formation is only $5 \%$ to $10 \%$. In 2016 , the annual production of tight oil in the United States reached $2.12 \times 10^{8} \mathrm{t}$, accounting for $52.6 \%$ of the total crude oil production in the United States. In the same year, the external oil dependence percentage in the United States dropped to about 33\%.

The development of tight oil reservoirs in China started relatively late [3]. So far, a number of tight oil reserves have been discovered in Ordos, Songliao, Junggar, and Bohai bay, but they are basically in the early technical stage [4]. The supporting technologies for tight reservoir development in the United States cannot be directly applied to tight reservoir development in China due to the following reasons: most tight reservoirs in the United States are marine deposits, with high pressure, high gas-oil ratio, high oil mobility, and brittle reservoir rocks. Most of the tight reservoirs in China are continental deposits with insufficient formation energy, 
low gas-oil ratio, crude oil of high viscosity, and high content of rock-plastic minerals, which negatively affect the fracturing of reservoirs. In contrast, China's tight reservoirs have a more complex geology, worse reservoir physical conditions, and more severe technical challenges. At present, China has not formed a mature development theory, experience, and equipment for the economic development of tight reservoirs, and the key technologies of tight reservoir development are still in the preparation stage before the breakthrough. China's tight oil reservoirs are still in their infancy due to the small scale, low production per well, and high development costs. In summary, the economic deviation of China's tight oil development poses a greater challenge to economic development [5].

Sand production is the inevitable problem in the development of tight oil fields. The prediction of sand production is now a popular research topic in both academia and industry. Generally, the sand production happens when the formation stress exceeds the rock strength, which is dominated by the cementation of cements, adhesion of fluids, and friction between particles[6]. The formation stress includes the structural stress, overburden stress, flow force, and production pressure difference [7]. The mechanical mechanisms of sand production include three failure types (Figure 1): (1) shear failure. The rock will exhibit the status of elastic deformation or plastic deformation while the effective stress of rock exceeds its compressive strength; (2) tensile failure. The flow channel for sand production will be generated if the stress exceeds the tensile strength; this is, the sand production will happen if the stress at the borehole is higher than the tensile strength; (3) bond failure. This mechanism is more significant in the weak cementation formation. The bond strength dominates the erosion of bare surfaces. The sand will be produced if the drag force caused by fluid flow is higher than the bond force [8]. Thus, a sand production prediction model is essential for sand control and well management [9].

The sand production is closely related with the petrophysical and fluid properties [10]. Many papers reported the sand production under the stress theory, classical sand production factors, sand production experiment, and effects of wetted fluid concentration on sand arch. Based on these studies, the main controlling factors for sand production are geology, well completion, and oil/gas production $[11,12]$. The geological factors include structural stress, interparticle bonding, and fluid properties [13]. Completion factors include borehole size, well deviation, and perforation. Production factors include production pressure difference, fluid flow in the formation, water injection, formation damage, and other factors. Transport of oil in the fractured tight reservoirs can be thought of as an advective-diffusive-reactive flow process [14]. Other factors include oil viscosity and rock wettability. Under the pressure decline, the viscosity of degased oil increases, and the wettability changes from water-wet to oil-wet. These will transform the capillary pressure from driving force to resistant force, which leads to the increase of dragging force of fluid and promotes the sand production[15]. However, previous studies are focused more on the qualitative methodology with considering very few factors. The sand production mechanism can only be deeply

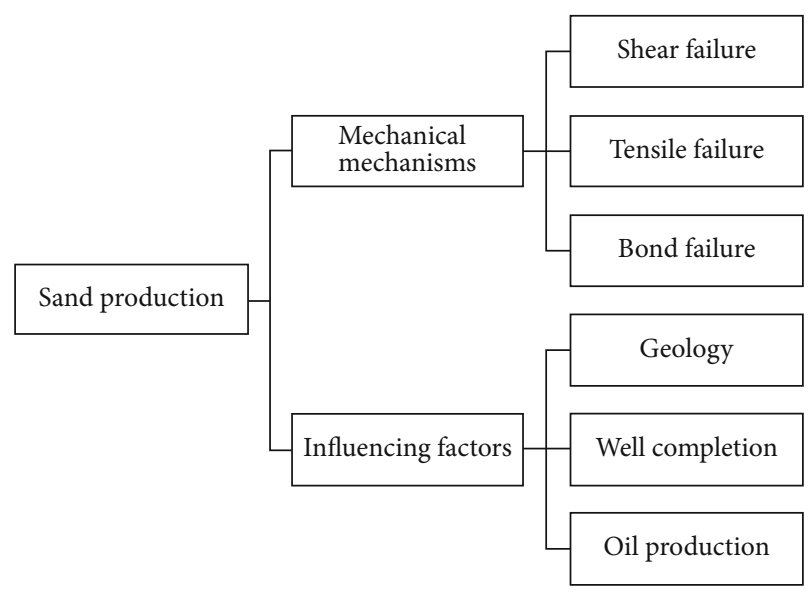

FIGURE 1: General sketch of the sand production problem.

understood by finding a clear relationship between rock properties, fluid flow, and sand production rate [16].

Few studies have been performed on sand production prediction for the tight sandstone oil reservoir [17]. In the industry, the sand production factors of the tight sandstone oil reservoir are still not clear, and factors resulting in the sand production risk are also in need to be explored [18]. Around the tight oil production wells after large-scale fracturing, rocks are cracked and destroyed under artificial action formation rock structure, so formation stress should be the main cause of sand production, and crude oil mainly flows into the bottom of the well through the fracture after fracturing. With the focus on these limitations, this study provides a sand production prediction model to dynamically assist the sand control.

Previous studies have mostly described the sand production mechanism qualitatively. In this paper, a quantitative calculation model for sand production of tight oil reservoir is obtained by combining the seepage law of tight oil with the analysis of well stress. The sand production prediction model in this study is firstly constructed by bridging the rock mechanical theory and fluid flow [19]. This model is secondly validated against the field data from the Daqing oilfield in Songliao Basin. The sand production mechanisms are thirdly discussed based on the model, which provides theoretical basis for the tight sandstone oil reservoir development [20-22].

Firstly, the seepage model of the tight sandstone oil reservoir is established to obtain the sand production within the sand production radius; then, the stress around the well is analyzed to calculate the sand production radius, and finally, the two are used to obtain the sand production from the tight sandstone oil reservoir.

\section{Model Establishment}

Due to the extremely low permeability of tight reservoirs, large-scale fracturing is generally required for production. The seepage of oil and gas in fractures follows Darcy's law, and the permeability of fractures is far greater than that of the formation matrix. Therefore, oil flow can be considered 


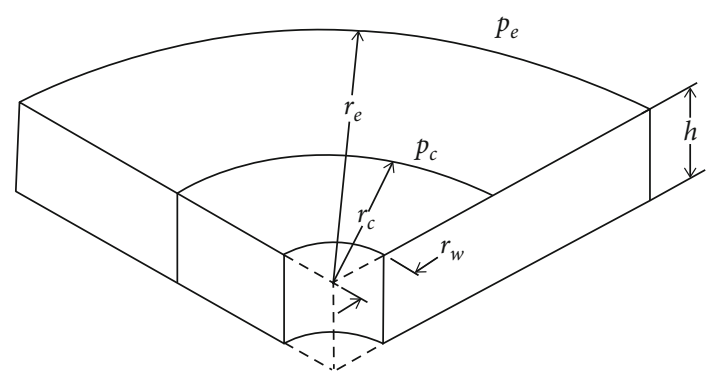

Figure 2: Circular finite oil reservoir model.

only through fractures during production, ignoring the formation bedrock oil production. The reservoir is assumed as a circular finite oil reservoir as shown in Figure 2. The reservoir thickness, the boundary radius, and the well radius are expressed as $h, r_{e}$, and $r_{w}$.

The main assumptions are as follows:

(1) Only the flow of oil and solid phases is considered

(2) Isothermal condition

(3) Effects of well completions on sand production are omitted

Under the plastic deformation, the relationship between the volume change and the shear velocity is as follows $[23,24]$ :

$$
\begin{aligned}
\frac{\partial v}{\partial r}+\gamma \cdot \frac{v}{r} & =\wedge \theta_{\alpha}\left(\frac{\partial v}{\partial r}-\frac{v}{r}\right), \\
\theta_{\sigma} & =\operatorname{sgn}\left(\frac{\partial v}{\partial r}-\frac{v}{r}\right) .
\end{aligned}
$$

The expansion coefficient $\wedge$ is related with radial stress; the flow-pattern coefficient $\gamma$ equals to 1 in the radial flow case and 2 in the spherical flow case. By solving equation (2), the solid velocity can be obtained as follows:

$$
\begin{aligned}
v & =\frac{C}{r^{n}}, \\
n & =\frac{\gamma+\wedge \theta_{\alpha}}{1-\wedge \theta_{\alpha}} .
\end{aligned}
$$

The oil and sand production rates can be calculated as equations (4) and (5), respectively:

$$
\begin{aligned}
& q_{f}=2 \pi r h w(r), \\
& q_{s}=2 \pi r h v(r) .
\end{aligned}
$$

For the sand production formation, the velocity difference between oil and solids can be calculated as follows:

$$
w-v=\frac{\beta K}{\mu} \cdot \frac{d p}{d r},
$$

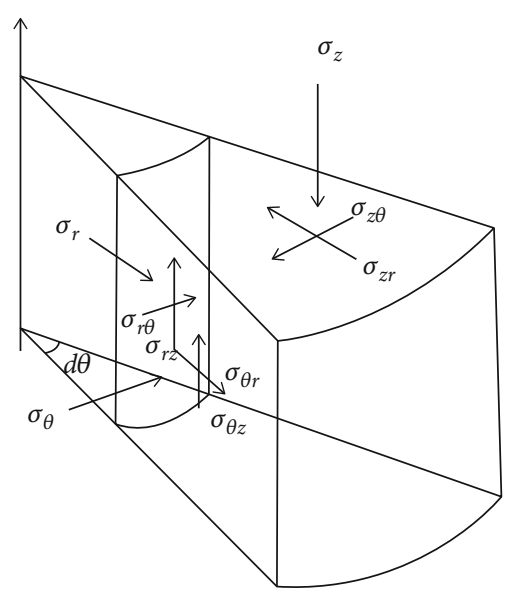

FIGURE 3: Microunit stress around the wellbore.

$$
\frac{q_{f}}{2 \pi r h}-\frac{C}{r^{n}}=\frac{\beta K}{\mu} \cdot \frac{d \mathrm{p}}{d r} .
$$

The integration procedure is as equations $(8)-(10)$ :

$$
\begin{gathered}
\int_{r_{w}}^{r_{e}} \frac{q_{f}}{2 \pi r h} d r-\int_{r_{w}}^{r_{c}} \frac{C}{r^{n}} d r=\int_{p_{w}}^{p_{e}} \frac{\beta K}{\mu} d p \\
\frac{q_{f}}{2 \pi h} \ln \frac{r_{e}}{r_{w}}-\frac{C\left(r_{c}{ }^{1-n}-r_{w}{ }^{1-n}\right)}{1-n}=\frac{\beta K\left(p_{e}-p_{w}\right)}{\mu}, \\
C=\frac{q_{f} / 2 \pi h \ln r_{e} / r_{w}-\beta K\left(p_{e}-p_{w}\right) / \mu}{\left(r_{c}^{1-n}-r_{w}{ }^{1-n}\right) / 1-n}
\end{gathered}
$$

The sand production rate can thus be obtained as follows:

$$
q_{s}\left(r_{w}\right)=\frac{\left[q_{f} \ln \left(r_{e} / r_{w}\right)-2 \pi h \beta K\left(p_{e}-p_{w}\right) / \mu\right](1-n)}{\left(r_{c}^{1-n} / r_{w}^{1-n}-1\right)} .
$$

The stress distribution around the well is studied by taking a microelement of the rock around the well, and the stress can be classified as radial stress $\left(\sigma_{r}\right)$, tangential stress $\left(\sigma_{\theta}\right)$, axial stress $\left(\sigma_{z}\right)$, and shear stress (Figure 3, $\sigma_{\theta r}, \sigma_{\theta z}$, and $\left.\sigma_{r z}\right)$.

The principal stress around the wellbore can be expressed by matrix eigenvalues $[25,26]$ :

$$
\left|\begin{array}{ccc}
\sigma_{r}-\sigma & \sigma_{r \theta} & \sigma_{z r} \\
\sigma_{\theta r} & \sigma_{\theta}-\sigma & \sigma_{\theta z} \\
\sigma_{z r} & \sigma_{z \theta} & \sigma_{z}-\sigma
\end{array}\right| r=0 .
$$


TABLe 1: Petrophysical parameters of the Daqing oilfield.

\begin{tabular}{lcccccc}
\hline $\begin{array}{l}\text { Average reservoir } \\
\text { pressure/MPa }\end{array}$ & $\begin{array}{c}\text { Reservoir boundary } \\
\text { radius/m }\end{array}$ & Well radius/m & Permeability $/ 10^{-3} \mu \mathrm{m}^{2}$ & Depth/m & Thickness/m Viscosity $/ \mathrm{mPa} \cdot \mathrm{s}$ \\
\hline 28.66 & 186.47 & 0.1015 & 2.3 & $2540-2536$ & 53.5 & 19.5 \\
\hline
\end{tabular}

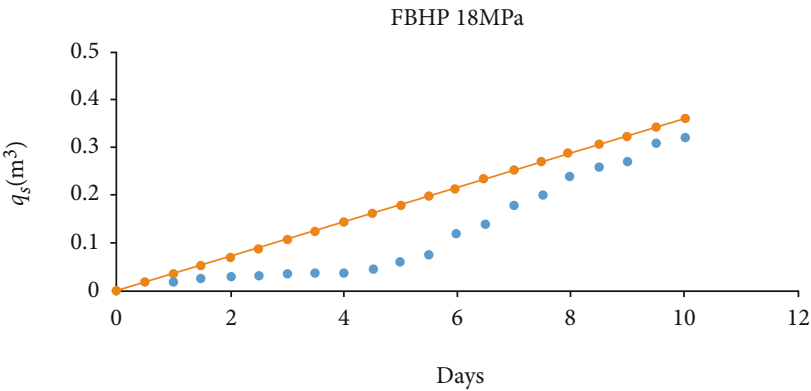

- Field data

- Calculating data

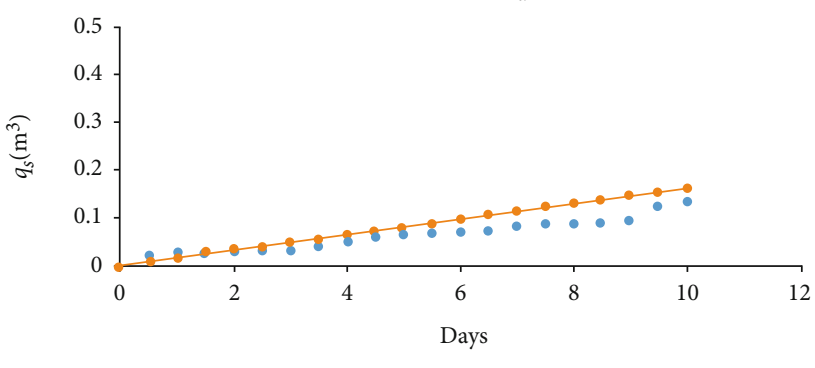

- Field data

- Calculating data

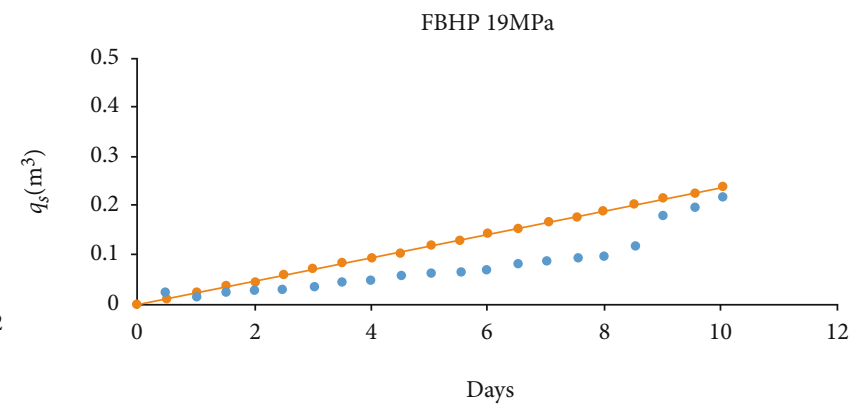

- Field data

- Calculating data

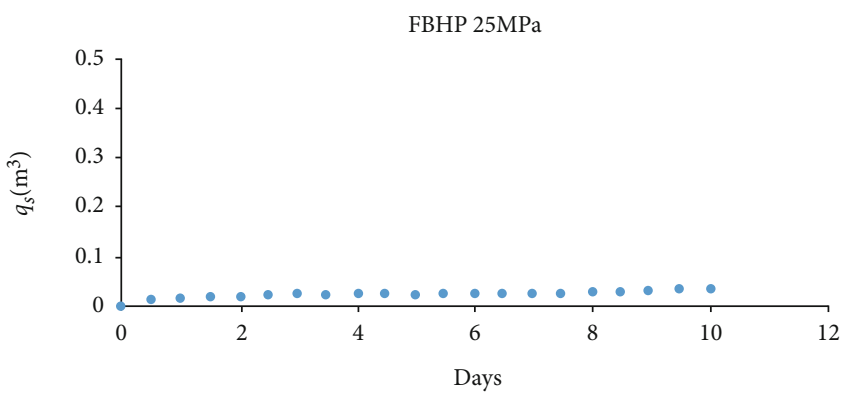

- Field data

FIGURE 4: Relationship between flowing bottom-hole pressure and sand production rate.

The principle stress can be got as follows:

$$
\left\{\begin{array}{l}
\sigma_{1}^{\prime}=\frac{-b-2 A \sqrt{\cos (\theta / 3)}}{3} \\
\sigma_{2}^{\prime}=\frac{[-b+(\cos (\theta / 3)+\sqrt{3} \sin (\theta / 3)) \sqrt{A}]}{3}, \\
\sigma_{3}^{\prime}=\frac{[-b+(\cos (\theta / 3)-\sqrt{3} \sin (\theta / 3)) \sqrt{A}]}{3}
\end{array}\right.
$$

where

$$
\begin{aligned}
& b=-\left(\sigma_{r}+\sigma_{\theta}+\sigma_{z}\right), \\
& c=\sigma_{r} \sigma_{z}+\sigma_{\theta} \sigma_{z}+\sigma_{r} \sigma_{\theta}-\sigma_{r}{ }^{2}-\sigma_{\theta}^{2}-\sigma_{z}^{2}, \\
& d=-\left(\sigma_{r} \sigma_{\theta} \sigma_{z}+2 \sigma_{r \theta} \sigma_{\theta z} \sigma_{z r}-\sigma_{r} \sigma_{\theta z}{ }^{2}-\sigma_{\theta} \sigma_{z r}{ }^{2}-\sigma_{z} \sigma_{r \theta}{ }^{2},\right. \\
& A=b^{2}-3 c, B=\mathrm{bc}-9 \mathrm{~d}, \\
& \theta=\arccos \left(\frac{2 A b-3 B}{2 A \sqrt{A}}\right) .
\end{aligned}
$$

The reservoir pressure is a function of flowing bottom- hole pressure (FBHP) within the boundary of sand production, which can be expressed as follows:

$$
p_{c}=p_{w}+\frac{p_{0}}{\ln \left(r_{e} / r_{w}\right)} \ln \frac{r_{c}}{r_{w}}
$$

especially when the radius equals to $r_{c}$

$$
\begin{aligned}
\sigma_{1}\left(p_{w}, r_{c}\right) & -\beta_{b} p_{p}\left(p_{w}, r_{c}\right)=2 Y \tan \left(\frac{\varphi}{2}+\frac{\pi}{4}\right) \\
+ & {\left[\sigma_{3}\left(p_{w}, r_{c}\right)-\beta_{b} p_{p}\left(p_{w}, r_{c}\right)\right] \tan ^{2}\left(\frac{\varphi}{2}+\frac{\pi}{4}\right) . }
\end{aligned}
$$

The maximum and minimum stress $\sigma_{1}$ and $\sigma_{3}$ can be obtained based on stress matrix:

$$
\begin{gathered}
\sigma_{1}\left(p_{w}, r_{c}\right)=\max \left\{\sigma_{1}^{\prime}, \sigma_{2}^{\prime}, \sigma_{3}^{\prime}\right\}, \\
\sigma_{3}\left(p_{w}, r_{c}\right)=\min \left\{\sigma_{1}^{\prime}, \sigma_{2}^{\prime}, \sigma_{3}^{\prime}\right\} .
\end{gathered}
$$

Calculate the value of $\sigma_{1}^{\prime}, \sigma_{2}^{\prime}$ and $\sigma_{3}^{\prime}$ at a certain radius, then the values of $\sigma_{1}$ and $\sigma_{3}$ are determined, and $\sigma_{1}$ and $\sigma_{3}$ are substituted into Equation (20). When Equation (20) is 


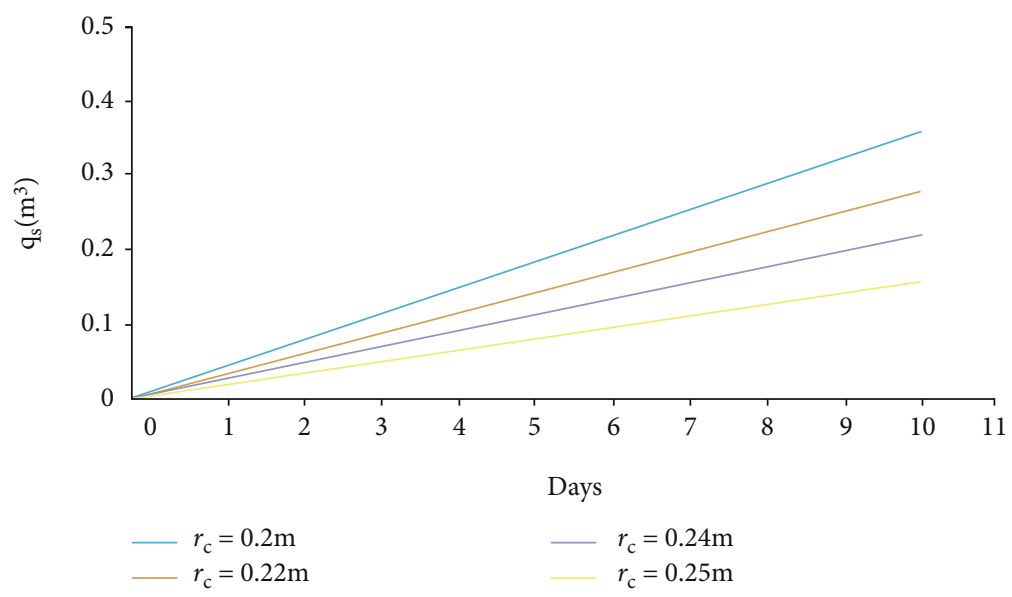

FIGURE 5: Relationship between the sand production rate and time under difference sand production radii (18 MPa).

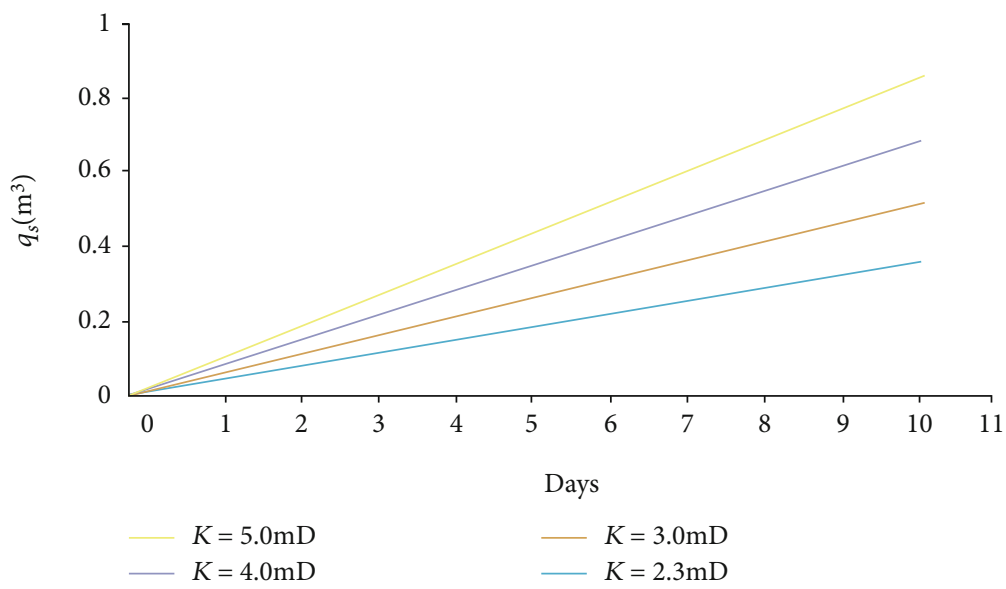

FIGURE 6: Relationship between the sand production rate and time under different permeabilities $(18 \mathrm{MPa})$.

equal, the radius is determined to be the sand producing radius $r_{c}$, so the sand quantity can be calculated according to Equation (11).

\section{Results and Discussions}

In order to validate the accuracy of the proposed model, the Daqing oilfield in Songliao Basin is selected. The parameters of this tight sandstone oil reservoir are shown in Table 1 . Based on these parameters, the critical FBHP of sand production is calculated and validated against real date.

Field measurement reports the critical FBHP which is $24.21 \mathrm{MPa}$, and the critical pressure difference is $4.45 \mathrm{MPa}$. This model provides an estimation of $25.27 \mathrm{MPa}$ for the FBHP, which has a relative error of $4.38 \%$ compared with field data. This validation indicates the proposed model is both practical and accurate.

3.1. Effects of Flowing Bottom-Hole Pressure on Sand Production. The sand production rate is related with FBHP. Figure 4 shows the sand production rate under FBHP of $18 \mathrm{MPa}, 19 \mathrm{MPa}, 22 \mathrm{MPa}$, and $25 \mathrm{MPa}$. The solid line is the sand production rate from the model, and the dotted points are the sand production rate from field measurement. With the time being, the FHP becomes smaller, and the sand production is easier. Specially, the sand production rate is the highest under the FBHP of $18 \mathrm{MPa}$. As the well completion factor is not considered in this model, thus the estimated critical BHP is higher than the real data. There are two types of sands during the sand production: (1) the free sands in the pores and (2) the detached sands from rock matrix. The sand production curve thus has an inflection point. With the time being, the relative difference between the model result and real data is smaller, which further shows the practical application of this model.

3.2. Effects of Sand Production Radius on the Sand Production Rate. The FBHP is significantly affected by sand production radius. With a larger sand production radius, the critical pressure difference will be higher. A larger sand production radius results in a lower sand production rate under a certain FBHP. Figure 5 shows the sand production rate under the FBHP of $18 \mathrm{MPa}$ and sand production radii of $0.20 \mathrm{~m}$, $0.22 \mathrm{~m}, 0.24 \mathrm{~m}$, and $0.25 \mathrm{~m}$. Overall, the possibility of sand 
production is larger with the increase of producing time. While a location is closer to the borehole, the moment of force on a particle is larger, which further results in a higher sand production rate. This is because the oil production rate near the borehole is high, and the rock failure is severe, which is caused by a quick change of oil saturation and pore pressure. Compared with the near-wellbore region, the possibility of sand production in the region far away from the borehole is much lower.

3.3. Effects of Permeability on the Sand Production Rate. The sand production rate is also significantly affected by the permeability. Figure 6 indicates the sand production rate under the FBHP of $18 \mathrm{MPa}$ and different formation permeabilites $(2.3 \mathrm{mD}, 3.0 \mathrm{mD}, 4.0 \mathrm{mD}$, and $5.0 \mathrm{mD})$. We can see that the sand production rate is higher with a larger permeability. This is because the oil rate is higher under a larger permeability, which leads to a rapid change of pore pressure and oil saturation.

\section{Summary and Conclusions}

Although the fluid seepage and stress distribution around the well have been considered in the development of tight sandstone reservoirs, the problems encountered in actual reservoir development are more complicated. For example, the non-Darcy seepage of the formation fluid, the multimedia seepage, and the complicated stress distribution around the well, this model does not consider the above problems, there are still deficiencies, and the calculation results still have errors compared with the actual situation.

The sand production prediction model is built based on the derivation of the sand production rate, which is well validated against the field data in the Daqing field with a relative error of $4.38 \%$. The main conclusions of this paper are as follows:

(1) The sand production rate of the tight sandstone oil reservoir is closely related with FBHP. While the critical pressure difference is exceeded, a higher FBHP leads to a lower sand production rate

(2) The critical FBHP is significantly affected by sand production radius. Under a certain FBHP, the sand production is more severe with a smaller sand production radius and a closer distance to borehole

(3) Different tight sandstone oil reservoir permeabilities result in various sand production rates. A higher permeability induced a more rapid change of pore pressure and oil saturation, which further increases the possibility of sand production

\section{Nomenclature}

Roman Symbols

$q_{f}: \quad$ oil production rate, $\mathrm{m}^{3} / d$

K: $\quad$ permeability, $10^{-3} \mu \mathrm{m}^{2}$

$h: \quad$ thickness, $\mathrm{m}$

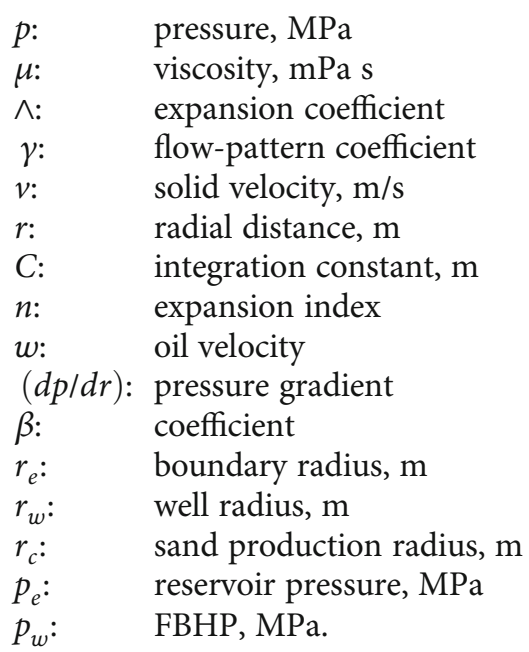

\section{Data Availability}

Data available upon request.

\section{Conflicts of Interest}

We declare that we have no conflict of interest.

\section{Acknowledgments}

The authors are grateful for CNOOC Key Research and Development Projects (CCL2019ZJFN1113), (CCL2019ZJFN1114), and (CCL2020ZJFN0314) and the Development of Natural Gas Hydrate Exploitation Mechanism and Simulation Platform (TSTAU-R2018018).

\section{References}

[1] US Energy Information Administration (EIA), "Outlook for shale gas and tight oil development in the US [EB/OL]," 2013, https://www.eia.gov/pressroom/presentations/ sieminski_05212013.pdf.

[2] EIA, "Tight oil remains the leading source of future U. S. crude oil production [EB/OL]," 2018, http://www.eia.gov/ todayinenergy/detail.php?id=35052.

[3] Y. Wang, L. Liu, S. Li et al., "The forming mechanism and process of tight oil sand reservoirs: a case study of Chang 8 oil layers of the upper triassic Yanchang formation in the western Jiyuan area of the Ordos Basin, China," Journal of Petroleum Science \& Engineering, vol. 158, pp. 29-46, 2017.

[4] M. M. Rahman and M. K. Rahman, "A review of hydraulic fracture models and development of an improved pseudo-3d model for stimulating tight oil/gas Sand," Energy Sources, Part A: Recovery, Utilization, and Environmental Effects, vol. 32, no. 15, pp. 1416-1436, 2010.

[5] X. P. Zhai, Y. S. Lou, B. S. He, and H. Ji, "Mechanical analyze of casing failure with sand production in loose sandstone reservoir," Applied Mechanics and Materials, vol. 217-219, pp. 2283-2286, 2012.

[6] A. Shabdirova, N. H. Minh, and Y. Zhao, "A sand production prediction model for weak sandstone reservoir in Kazakhstan," Journal of Rock Mechanics and Geotechnical Engineering, vol. 11, no. 4, pp. 760-769, 2019. 
[7] H. Rahmati, M. Jafarpour, S. Azadbakht et al., "Review of sand production prediction models," Journal of Petroleum Engineering, vol. 2013, Article ID 864981, 16 pages, 2013.

[8] J. Deng, L. Wang, P. Li, and W. Zhao, "The critical pressure difference prediction of sand production in deepwater sandstone gas reservoirs," Petroleum Science and Technology, vol. 31, no. 19, pp. 1925-1932, 2013.

[9] A. W. Martinius, M. Fustic, D. L. Garner et al., "Reservoir characterization and multiscale heterogeneity modeling of inclined heterolithic strata for bitumen-production forecasting, McMurray formation, corner, Alberta, Canada," Marine and Petroleum Geology, vol. 82, pp. 336-361, 2017.

[10] R. Gholami, B. Aadnoy, V. Rasouli, and N. Fakhari, "An analytical model to predict the volume of sand during drilling and production," Journal of Rock Mechanics and Geotechnical Engineering, vol. 8, no. 4, pp. 521-532, 2016.

[11] L. Wang, Y. Tian, X. Yu et al., "Advances in improved/enhanced oil recovery technologies for tight and shale reservoirs," Fuel, vol. 210, pp. 425-445, 2017.

[12] C. Dong, X. Chen, Y. Chen, R. Kang, and R. Feng, "Experimental study on mechanism and capability of sand-carrying in water-producing gas wells and its application," Journal of China University of Petroleum, vol. 38, no. 6, pp. 90-96, 2014.

[13] A. Fadairo, O. Oyedele-Adeyi, A. Oladepo, and T. Ogunkunle, "Modeling the effect of entrained sand particles on pressure transverse in a flowing gas well," World Journal of Engineering, vol. 14, no. 5, pp. 406-413, 2017.

[14] M. Dejam, "Advective-diffusive-reactive solute transport due to non-newtonian fluid flows in a fracture surrounded by a tight porous medium," International Journal of Heat and Mass Transfer, vol. 128, pp. 1307-1321, 2019.

[15] S. F. Xue, G. S. Ma, L. G. Yu, and H. K. Ge, "Fluid-solid coupling model and its application in quantitative sand production prediction of oil and water wells," Petroleum Exploration \& Development, vol. 34, no. 6, pp. 750-754, 2007.

[16] E. Khamehchi and E. Reisi, "Sand production prediction using ratio of shear modulus to bulk compressibility (case study)," Egyptian Journal of Petroleum, vol. 24, no. 2, pp. 113-118, 2015.

[17] M. B. Oyeneyin and B. Moriwawon, "Sand production forecasts for unconsolidated gas reservoirs," Advanced Materials Research, vol. 62-64, pp. 466-473, 2009.

[18] National Energy Board, Energy briefing note, tight oil developments in the western Canadian Sedimentary Basin, National Energy Board, Calgary, 2011.

[19] L. Dengsheng, S. Lin, and C. Lei, “The flow research of gas-oilsand three phase in wellbore with heavy oil reservoir," 2011 International conference of environmental science and engineering, vol. 12, pp. 318-324, 2012.

[20] P. G. Ranjith, M. S. A. Perera, W. K. G. Perera, B. Wu, and S. K. Choi, "Effective parameters for sand production in unconsolidated formations: an experimental study," Journal of Petroleum Science and Engineering, vol. 105, pp. 34-42, 2013.

[21] M. R. Zare-Reisabadi, A. Kaffash, and S. R. Shadizadeh, "Determination of optimal well trajectory during drilling and production based on borehole stability," International Journal of Rock Mechanics and Mining Sciences, vol. 56, pp. 77-87, 2012.

[22] M. Khammar and Y. Xu, "Batch solvent extraction of bitumen from oil sand. Part 2: experimental development and modeling," Energy \& Fuels, vol. 31, no. 5, pp. 4626-4636, 2017.
[23] S. Walspurger, G. D. Elzinga, J. W. Dijkstra, M. Sarić, and W. G. Haije, "Sorption enhanced methanation for substitute natural gas production: experimental results and thermodynamic considerations," Chemical Engineering Journal, vol. 242, pp. 379-386, 2014.

[24] S. B. Grafutko and V. N. Nikolaevskii, "Problem of the sand production in a producing well," Fluid Dynamics, vol. 33, no. 5, pp. 745-752, 1998.

[25] T. Xu and C. A. Tang, "Modeling of stress-induced permeability evolution and damage of rock," Advanced Materials Research, vol. 33-37, pp. 609-616, 2008.

[26] D. R. Schmitt, C. A. Currie, and L. Zhang, "Crustal stress determination from boreholes and rock cores: fundamental principles," Tectonophysics, vol. 580, pp. 1-26, 2012. 